\title{
EXPERIENCES OF HARM REDUCTION AMONG WOMEN WITH ALCOHOL USE PROBLEMS
}

\author{
CATRINA G. BROWN, \\ School of Social Work, Dalhousie University, Halifax, \\ SHERRY H. STEWART, \\ Department of Psychiatry and Psychology, Dalhousie University, Halifax \\ and \\ SARAH E. LARSEN \\ Department of Psychology, St. Mary's University, Halifax
}

\begin{abstract}
This paper explores women's choice of controlled drinking or abstinence goals in harm reduction treatment programs for alcohol use problems. Situated within debates about controlled or abstinence goals for alcohol use, this research project provides a specific focus on women's treatment needs. We explore evidence which reveals that women in treatment for alcohol problems often hold deeply internalized dominant social ideologies on addiction. Results demonstrate that while offered the choice of abstinence or controlled use goals, most women defined themselves as "addicts," adopted a disease metaphor of "addiction," and chose abstinence. The findings here raise questions about whether or not clients receive sufficient education about harm reduction and controlled drinking and make adequately informed choices.
\end{abstract}

Practiced in western Europe for over twenty years, and supported by the World Health Organization (Room, 1997; WHO, 1996), harm reduction strategies have only recently become a viable alternative for women struggling with alcohol use problems in North America. Harm reduction philosophy appeals to women-centered practitioners because it departs from dominant deficit-based, abstinence-focused, diseasemodel interpretations of addiction (Denning, 2000). Harm reduction approaches offer strategies toward change that are harmonious with those of women-centered practice, emphasizing client empowerment, self-determination/choice, and the necessity of clients’ setting their own goals (Bepko, 1991; Pasick \& White, 1991). Harm reducetion is defined by leading proponent, Tatarsky (1998) as "a pragmatic approach that accepts active substance use as a fact and assumes that substance users must be engaged where they are, not where the provider thinks they should be. It recognizes that substance use and its consequences vary along a continuum of harmful effects for the user and the community, and that behaviour generally changes by small incremental steps” (p. 10). The essence of harm reduction philosophy reflects non-moralistic values and centres on individuals making their own treatment choices, practice prag-

This research was supported through a generous grant from the Nova Scotia Health Research foundation to the first and second authors. The authors would like to acknowledge the assistance of Health Services Director Tom Payette (Capital District Health Authority), Program Managers Paul Helwig (Core), and Jean McClelland (Matrix) as well as service providers at each of these programs for their assistance in recruiting participants for the study. We would also like to thank Jennifer Theakston for her research assistance. And of course, we extend our thanks to the women receiving services at these programs for their participation in the study. 
matism and compassionate strategies to minimize harmful consequence (Blume, Anderson, Fader, \& Marlatt, 2001; Denning, 2000; Erickson, Riley, Cheung, \& O’Hare, 1997; Inciardi \& Harrison, 2000; Tatarsky, 2002). Thus, clients are not required to give up existing coping strategies without having alternative tactics in place. Harm reduction offers an alternative to the "just say no," "zero tolerance," and "war on drugs” public policy, programming, and treatment approaches (Marlatt, Larimer, Baer, \& Quigley, 1993). Similar to a client-centred approach, harm-reduction philosophy and treatment is collaborative in setting goals and determining interventions.

Heather (1993) outlines four central approaches in applying harm-reduction principles to the treatment of alcohol problems. The first approach he calls "drinking but improved," referring to the status of clients who continue to drink and demonstrate related problems following treatment, but whose alcohol intake levels and the severity of the problems are reduced. The second approach he identifies as "the wider criteria of treatment outcome" which emphasizes the client's overall quality of life. The ultimate objective of treatment is not total abstinence or harm-free drinking but simply an improvement in the client's overall quality of life. Third, Heather describes “controlled or 'harm-free' drinking.” He notes that "this is in fact what most people think of when they apply the idea of harm reduction to the alcohol problems field” (p. 174). Within this approach, controlled drinking can be an outcome category following abstinence-oriented treatment or a goal of treatment itself. This approach involves the complete elimination of alcohol-related harm and thus it can be argued involves harm reduction in its most extreme form. Last is "harm reduction from a societal perspective" which refers to reduction of the total number of problems caused by alcohol in a given society. These approaches are not necessarily mutually exclusive; neither are harm reduction strategies for treatment separate from an overall philosophy of harm reduction.

In this paper, we explore women's choice of controlled drinking or abstinence goals within programs that use harm reduction to treat alcohol use problems. This paper emerges from the portion of our community-based research which explored women clients' views on harm reduction based treatment for women in alcohol treatment (Stewart, Brown, Theakston, Devoulyte, \& Larsen, 2004). We will begin by reviewing the debate on controlled use of alcohol among those with alcohol problems, and then present the study and its findings. We explore evidence revealing that women in treatment for alcohol problems often hold deeply internalized dominant social ideologies on addiction (Sanders, 1998; Winslade \& Smith, 1997). Results demonstrate that while offered the choice of abstinence or controlled use as treatment goals most women defined themselves as "addicts," adopted a disease metaphor of "addiction," and chose abstinence. Consistent with Heather's (1993) observation, most women in this study understood harm reduction only to mean adopting controlled drinking goals. The implications of these findings is that current harm reduction based treatments need to provide sufficient information to women to empower them to make truly informed choices.

\section{CONTROLLED DRINKING VERSUS ABSTINENCE}

Harm reduction emerged in the 1980s, most notably in the Netherlands and Britain, as a public health response intended to reduce HIV risks associated with the use of drugs (Denning, 2000; Inciardi \& Harrison, 2000; Tatarsky, 1998). The Dutch policy alternative, situated between the "war on drugs" approach and legalization, is one of "normalization" (Dorn, 1989; Engelsman, 1989). With a co-emphasis on the 
needs of the individual, and the goal of minimizing of all forms of harmful impact, normalization avoids stigmatizing and labelling (Dorn, 1989). In contrast to American policy, which continues to promote zero tolerance despite international trends, the Canadian government redirected its drug-policy position to one which emphasized harm reduction in 1987 (Fischer, 1997). Moving beyond a "one-size-fitsall" model and responding to poor efficacy in traditional approaches, harm reduction seeks to be more flexible, comprehensive, and inclusive (Miller, 1983). Harm reducetion or low-threshold treatment approaches signify an important public health direction because what they offer may be a more attractive option to reticent individuals (Englesman, 1989; Marlatt et al., 1993). Requiring clients to commit to abstinence before they are adequately equipped not only sets them up for failure, it may prevent them from seeking help at all (Tatarsky, 1998). This research project is situated within debates about controlled or abstinence goals for drinking outcomes (Marlatt, 1983), but provides a specific focus on women's treatment experiences. Women's addiction research demonstrates that research about men cannot necessarily be generalized to women (Greenfield, 2002; Najavits, 2002; Plant, 1997). This study contributes to filling a significant gap in the research on harm reduction in women's treatment programming.

A debate among health professionals working with alcohol addictions began to emerge in the 1960s over abstinence or controlled-drinking goals (Miller, 1983). Early research findings by Davies (1962), Sobell and Sobell (1973, 1976), and the Rand report (see Armor, Polich, \& Stambul, 1978) challenged the traditional foundational assumptions guiding alcohol addiction research and service delivery, calling into question the deeply contestable nature of "alcoholism.” These researchers argued that controlled drinking was possible among certain problem-drinking populations, confronting the core belief that addictions are a primary and progressive chronic disease (Fingarette, 1988; Marlatt et al., 1993; Peele, 1985a, 1985b). According to the disease model, alcoholism is characterized by impaired control over alcohol use, meaning, according to Marlatt and his colleagues, that "alcoholics have one of two options: to abstain or to continue drinking in a progressively deteriorating manner" (p. 464). Addictions are thus conceptualized as an all-or-nothing phenomenon whereby one either has, or does not have, the disease of alcoholism and from which less severe forms of drinking, such as problem drinking, or binge drinking/episodic drinking are indistinguishable (Marlatt et al., 1993). From this traditional deterministic perspective, alcoholism is a genetic or biologically caused disease outside of individuals' control, necessitating abstinence-based treatment. Additionally, when considered a primary disease, alcohol use as a secondary response, to the trauma of sexual violence or to depression, for example, is discounted. By definition, the alcoholic within this framework is unable to moderate or control alcohol use, and therefore a controlled or managed approach to drinking is not only unacceptable, it is also unthinkable.

Collectively reporting on over twenty years of research findings, Miller (1983), Sobell and Sobell (1995), and Marlatt et al. (1993) agree that moderated or managed drinking is as achievable a treatment goal as abstinence among those with less severe drinking problems. Of 22 research studies surveyed, 21 demonstrate the effectiveness of controlled drinking (Marlatt et al., 1993; Miller, 1983). Although generally more effective for less severe dependence, a minority of heavy drinkers have been successful at controlled drinking, suggesting potential for controlled drinking as a treatment option for all types of alcohol abuse (Finney \& Moos, 1981; Heather, 1995). Some speculate that the establishment of more effective forms of intervention, 
including training in moderation, could increase success in controlled drinking among heavy drinkers (Miller, 1983).

For decades, research has supported the effectiveness of the controlled-drinking approach, consistent with predictions of the philosophy of harm reduction. However, the debate about the utility of controlled-drinking verses abstinence approaches continues, and the disease model for understanding and treating addictions remains dominant especially in the United States (Marlatt et al., 1993). Recently the controversy surrounding controlled drinking has been defused by reframing it in the context of public health, shifting the focus from the politics of defining addiction to early intervention and prevention. The debate is hardly over, however; ideological differences remain entrenched in North America (Anderson, 1995; Weisner, 1995).

Research offers some important predictors of a successful moderate drinking outcome. Women are found to have greater success with a moderate-drinking approach than men and this is significant for women's treatment programming (Connors \& Walitzer, 1997; Marlatt et al., 1993; Marlatt, 1998; Miller \& Joyce, 1979; Rosenberg, 1993; Sanchez-Craig, Leigh, Spivak, \& Lei, 1989; Sanchez-Craig, Davila, \& Cooper, 1996). Investigation of the controlled-drinking research (see Heather \& Robertson for review, 1981; Ogborne, 1987) suggests the following are predictors of successful controlled drinking: lower dependence severity, younger age, regular employment, a person's confidence in his/her ability to abstain, a shorter history of drinking problems, post-treatment social support, and "less contact with Alcoholics Anonymous, and more ideological flexibility about treatment” (Heather \& Robertson, 1981, p. 478). In contrast, successful abstinence was predicted by prior efforts at abstinence, greater involvement with Alcoholics Anonymous, physician referral, and self-definition as an alcoholic. These findings suggest that the more individuals are exposed to and internalize dominant/traditional notions of addiction through abstinence-based treatment, the more they are likely to develop alcoholic identities. Those individuals less influenced by the dominant disease discourse appear to have better success with the controlled-drinking approach. In other words, if clients believe controlled drinking is possible, they are more likely to succeed. Orford and Keddie (1986) suggest that success at either abstinence or controlled use is directly linked to personal ideology and confidence in the approach (cited in Marlatt et al., 1993).

Research suggests that when clients' treatment reflects their goal choice of abstinence or controlled use, they are more likely to have favourable treatment outcomes (Booth, 1984; Marlatt et al, 1993; Marlatt, 1998). In a Canadian study by Ogborne (1987), it was demonstrated that those with more severe drinking problems tended to choose abstinence while younger people with less severe alcohol problems chose controlled drinking.

\section{RESEARCH OBJECTIVES}

This paper focuses on women's experiences and perceptions of harm reduction treatment and is part of a larger study. ${ }^{1}$ The purposes of the larger study were twofold. First, we attempted to understand the mechanisms underlying the coprevalence of binge eating and binge drinking among women receiving treatment for alcohol use problems, the results of which are presented elsewhere (see Stewart et al., 2004). Second, we explored perceptions and experiences of harm reduction with the intent of contributing toward improvement of current harm-reduction models for treatment. In particular, there is a lack of harm-reduction programming deliberately 


\section{HARM REDUCTION AND WOMEN}

designed to address the specific needs and experiences of women (Marlatt, 1998). It is the second objective that we address in the current paper.

\section{METHOD}

Data were gathered through multi-method research which included standardized questionnaires, semi-structured qualitative interviews, and a focus group. ${ }^{2}$ Fifty-eight adult women (aged 18 years or older) seeking treatment for alcohol abuse or dependence at Addiction Prevention and Treatment Services of the Capital District Health Authority in the Halifax Regional Municipality, Nova Scotia were recruited for this study. In order to be eligible, women had to be in treatment for a substance use problem, self-identify with an alcohol use problem, and screen positive for a clinically significant alcohol use problem using the 10-item Brief Michigan Alcoholism Screening Test (b-mast; Pokorny et al., 1972). All of the women who selfidentified as problem drinkers by appearing for the study met criteria for a likely alcohol use disorder on the screening test. Following completion of the questionnaires, women who identified as both binge eaters and binge drinkers, and who were interested in participating, were interviewed and subsequently invited to participate in the focus group. This paper focuses specifically on the data that emerged on harm reduction from qualitative interviews among 18 women service users, and a focus group of three women service users.

\section{Qualitative Interviews and Focus Groups ${ }^{3}$}

Qualitative interviews and focus groups emphasize women's own perceptions of their behaviours and the meanings they attached to them (Mies, 1983, 1991; Stanley \& Wise, 1990). Interviewers sought to establish rapport with the research participants in order to evoke richer accounts of their experiences (Finch, 1984; Oakley, 1981). These two-hour-long qualitative, semi-structured, audio-taped interviews focused on women's perceptions. Women's choice of abstinence or controlled use of alcohol, and their perceptions of harm-reduction approaches to treatment were investigated by exploring women's own stories.

Data analysis identified dominant themes and narratives that emerged from these interviews around reported treatment choices. We looked for both commonalities and disjuncture in women's narratives to examine transferability of the stories across different women's experiences. Data were collected until no new themes emerged. The focus group provided an additional layer of data beyond that obtained with the individual interviews (Connors \& Franklin, 2000; Kitzinger, 1994; Morgan, 1998).

\section{Data Analysis}

Data analysis identified dominant themes and narratives that emerged with respect to women's alcohol use and treatment choices. Data from the service users' interviews and focus group were seen to represent women's stories. A hermeneutic or interpretive approach was used to explore the meaning of women's stories. Thematic analysis involves "a search for and identification of common threads that extend throughout an entire interview or set of interviews” (Morse \& Field, 1995, p. 139). Attention to diversity is a critical component of all feminist research, thus this research explored the differences and commonalities in women's narratives (Reinharz, 1992), and determined transferability of these stories across different women's experiences. 
The data analysis on harm reduction involved overlapping techniques of thematic analysis and grounded theory, axial and selective coding. Drawing upon grounded theory (Glaser \& Strauss, 1967; Hurst, 1999; Strauss \& Corbin, 1990; Stern \& Pyles, 1985), open coding initially generates categories, axial coding makes connections between identified categories, and selective coding integrates the categories through uncovering the dominant story, or "explicating the story line" in the stories told (Strauss \& Corbin 1990, p. 119). Because stories cannot encompass the richness of lived experience, selective coding enabled us to note gaps, contradictions, and notable omissions in the women's stories (White \& Epston, 1990). Taken together, these strategies allowed us to unpack, contextualize, and interpret the narratives produced in this study. By exploring narratives in this manner, we determined how stories were organized to give meaning, structure, and coherence to the events or experiences in the participants' lives. This is highly congruent with the social constructionist and hermeneutic foundation of this study, whereby one explores the social construction of meaning through the stories told. Since stories only emerge within available social discourses, the data analysis attempts to situate women's stories about problem drinking within the larger social discourses on drinking behaviour and addiction discourse. Specifically, the choices women make between abstinence and controlled use within harm reduction programming are situated within the influence of dominant addiction discourse.

\section{FINDINGS}

This study explored views of women receiving harm reduction based treatment for alcohol use problems on harm reduction as a treatment strategy. The mean age of the 18 women participating in the open ended interviews was 38 years of age. Women interviewed had an average education level of 14 years. Most described themselves as Caucasian. Limited income and unemployment were a concern for 13 of the 18 women. Within their local treatment programs, clients could choose between abstinence or controlled-use goals. All of the women interviewed for this study were part of harm-reduction-based programming offered through Addiction Prevention and Treatment Services, Halifax Region, Nova Scotia. All of the women were also part of a women-specific program (Matrix), or one that had womenspecific components (Core). Although both Matrix and Core provide an initial orientation to harm reduction, many women were unclear about what harm reduction was. When asked about harm reduction, Jane ${ }^{4}$ said, "What do you mean?" She continued, "No, I've never had that attitude . . . It was always all-or-nothing." Similarly, when asked about harm reduction, Chelsea asked, "Which is what?"

Most of the women interviewed confused harm reduction with controlled drinking, not understanding that harm reduction emphasizes clients' choice of treatment goals including abstinence. Based on this assumption, they often concluded that they didn't believe in harm reduction. While the women didn't suggest people shouldn't be given the choice between controlled-drinking or abstinence goals, most were sceptical that controlled drinking as a choice was really possible. Although the women interviewed adopted either an abstinence or a controlled-drinking goal, we will begin by presenting findings from the most common group, women who chose abstinence and who reported that they did not generally support a harm-reduction approach to alcohol use problems. 


\section{Totalizing Identity Conclusions: "I'm an Alcoholic"}

Women who disagreed with harm reduction often concurrently believed that they were "addicts," and must abstain from alcohol use. Such totalizing identity conclusions tend to be rooted in the belief that they have a chronic primary disease which, by definition, requires abstinence. Molly-Anne stated, "I think 'once an alcoholic always an alcoholic.' I can't see going back to being a social drinker.” Mary adopted these same conclusions: "An alcoholic will find liquor. It doesn't matter where," and "addicts do things differently. ... ." According to Sarah, "I knew for a long time that I was an alcoholic. It was just a matter of facing it.”

In addition to adopting totalizing and often pathologizing identities, some women framed awareness of underlying motives for drinking as "an excuse," failing to see the value in exploring drinking motives. Because these women defined harm reduction primarily in relation to the concept of abstinence, they often focused on establishing absolute behavioural control of their drinking. This approach tended to minimize more introspective or self-reflective components of harm-reduction practice such as increasing awareness of underlying motives or emotional needs and discovery of new coping strategies in order to make different choices. Self-reflection sets up a dualistic choice for women: they can either become more aware of the underlying motivations for behaviour, and thus be more in control of their choices and behaveiours around drinking, or they can simply abstain which may not involve attending to these motivations at all. Framing the development of greater understanding or selfawareness as an excuse for drinking illustrates this dualism. When asked about her underlying reasons for drinking Mary established that she didn't have any legitimate reasons: "They are all just excuses.” She states emphatically,

No, none [referring to reasons for drinking]. Like I say, I'm an alcoholic. I use any excuse. . . . I can have any reason. . . . I can stub my toe. Any reason. I'm an alcoholic. Any reason at all. I can be mad. I can be happy. I can have a good day. I can say: “you know, I'm feeling good. I'm going to have a couple drinks.” You know? I can be doing housework. Any reason. I'm an alcoholic. I don't need an excuse or reason. I just do it.

Mary's thinking about her drinking behaviour is unhelpful to her in four ways. First, the belief that she has no control over her drinking denies her agency, choice, and self-determination. Second, she denies that she has any reason for her actions (i.e., benefits of drinking). Third, it reveals a lack of compassion toward herself through the minimization of the importance of her needs and feelings. She is only able to see her needs and feelings as impediments to abstinence. And fourth, this thinking does not require her to be self-reflective, an important step in avoiding relapse itself. This client stance raises significant questions about harm-reduction strategies which emphasize choice as though all choices were equal or had equal effect. In this instance, Mary's choice to abstain seems to be conflated with a refusal to enter into a dialogue about her emotional needs.

Most women were adamantly opposed to the use of controlled drinking and the philosophy of harm reduction for alcohol use problems primarily because they were committed to the idea of abstinence as evidence of recovery and because they didn't believe they had control over making the choice to drink. Describing a local harmreduction program, Shelley said, “. . . you'll find that . . . anybody that takes groups seriously are in abstinence and aren't using." She was very positioned on the issue of abstinence: "If you want to stay clean, you have to give up the habits that make you use." She had no confidence in a local program that was ". . . an ineffective program . . . because [it] was not a . . . program where you had to abstain from use.” For 
Shelley, being serious about addressing an alcohol use problem necessarily meant abstinence. Mary also held onto the idea of abstinence: "I don’t want it [alcohol] having any more control over my life-period. And once I take that first drink, I don’t have control anymore."

\title{
Experiences of Control
}

Abstinence is often the preference for women with drinking problems because they believe they have very little, if any, control over alcohol. Jane felt that drinking wasn't a choice once she had started: “If I start up again, then it starts all over again and it's almost like I don't have control. But before I take that first step to drinking yes, there is a choice.” Similarly, Taylor reported difficulty controlling her drinking: “. . . of course one drink leads to another to another." Claire agreed, "I know I can’t have any." For, Sarah, like many of the women interviewed, the goal was to "get sober." Sarah, an Alcoholics Anonymous member, has also experienced a lack of control over her drinking: And every time I drank, I'd binge drink. I couldn't have just one. I don't think personally one drink for me is ever going to work. I know that I'll never be able to drink socially."

Regarding controlled drinking, Sarah said, “God no. It doesn’t work for me.” Perhaps more strongly, Paula said, about controlled drinking, "That's a joke.” Ginnie stated, "For me, control means I don't ever want to do it again.” While she has tried a controlled-drinking approach, she has never felt that drinking was actually in her control. In agreement Paula said, "The alcohol takes a hold of me. I have no control over it anymore. . . . The drinking I can't control.” Mary didn't perceive herself to have any control over alcohol either:

\begin{abstract}
And I know when I sit down to drink that ... and I can use any excuse ... I can give you any excuse in the book. I've tried them all. I can be mad. I can be happy. I can be upset. I can be nervous. I can be scared. I can be whatever I want to be. But it's because my mind ... whatever chemical is released in your brain when you get to that certain point ... once you think about that first drink and you're fighting that first drink, you've already lost the battle. You've got to stop fighting an enemy that you can't win. And start running from it instead. Which I find to be true. I mean, if I'm going to continually think about a drink, then I'm going to drink it. I've already lost the battle.
\end{abstract}

This thinking encourages binge drinking: if having one drink is perceived as failure, it makes no difference whether one has one drink or many.

\section{Contradictions, Gaps and Uncertainties}

Most of the women interviewed adopted an either-or position on choice and the possibility of control over alcohol use. Shelley stated:

Like, I take one drink, I lose control . . . Because I've tried . . . controlled drinking. You know, I did real good at controlled drinking for about three years. But sooner or later, you don't do it anymore. ... But I was going out and having three more often. And I was looking forward to the three. It was just an illusion of control. Do you know what I mean? It's an illusion. ... I was talking myself into going out and getting drunk. . . . But you know what? It's a disease. It's not a social issue, it's a disease.

Contradicting this position, however, she later states:

I made a conscious decision to drink. Because now I make a conscious decision not to drink. I always said I made a conscious decision to drink. It's like in our program people will say: "I relapsed . . . I went out drinking and it just 
happened.” It never just happens. You make a decision to do it. I make a decision not to go to a liquor store.

Thus, on the one hand Shelley stated that she has no control over drinking (i.e., she has one drink and she loses control), and on the other, she stated she does have control (i.e., she makes a decision to drink and a decision not to drink). Although she was able to engage in controlled drinking for three years, she interpreted her difficulty to continue to do so as evidence that controlled drinking is not possible. An equally plausible interpretation is that controlled drinking is possible for her. Contradictory positions on whether women did or did not have control over their choice to drink were not uncommon among the women we interviewed in this study and are suggestive of the need to address this in harm-reduction programming.

Shelley's further statement highlights the contradiction around whether her drinking problem is a disease or about underlying psycho-social mechanisms which motivate the need to drink. While she referred to herself as an addict, and her drinking problem as a disease, she also revealed unmet emotional needs that she addresses through alcohol use: "I don't know how to take care of my needs, because my needs were never taken care of. I don't have any role models.”

Similarly, Mary does not believe in harm reduction and her absolutist thinking about alcohol use is evident here. Mary shared that she felt her desire for alcohol may become so out of control that she needed to put herself in someone else's hands.

So I've signed a consent form and she has my permission to do whatever is necessary to get me out of the house. Because I can't stay there. They have liquor there. And, you know, I don't think its right that they should have to get the liquor out of the house because I'm there. Or, lock the cabinets or anything. . . . [T]here's liquor everywhere in the world, and if not there, I'll go get it someplace else.

However, while Mary talked about not believing that harm reduction works for her, she does adopt a harm reduction approach with her medication. She has decided to take control over medication that doesn't mix well with alcohol.

This time leave them in your purse . . . you control them . . . you have control over this. You leave them in your purse. But you go home, you tell your mother, your sister, the lady you live with, your boyfriend, and whoever that they are in your purse. So if you do start drinking take them from you. But you control this. You put them in your purse and you control them yourself.

Although Mary repeatedly described her scepticism of harm reduction, she proceeded to dispute the "cold turkey approach" and appeared to be a proponent of "weaning off" which constitutes a step-down strategy within the harm reduction approach. It is possible that her contradictory stance may stem from a lack of information about what harm reduction is.

But I've tried all kinds of different ways. I've tried cold turkey. Cold turkey doesn't really work for me. Where, like you say, the weaning off part does. Which I did do. A lot through my . . . through this last year of working the program, I did do a lot of weaning off stuff.

Like Shelley, Mary views her use of alcohol as a disease, and as an addiction and she is reluctant to explore her emotional life. Despite not wanting to analyze her drinking motivations, seeing this as letting herself off the hook or providing herself with excuses, she did actually provide an account of using alcohol as a method of shutting down. She stated: "When I take that first drink ... I want to shut down. I want to be left alone. I want everybody to leave me alone." Given her description of using alcohol as a way to "shut down," the desire to avoid her emotional world may 
well be a primary motive of alcohol use. Therefore, although a significant theme for Mary was that she drinks because she is an alcoholic - and, as such, doesn't need a reason-wanting to shut down, and using alcohol to do so, was a competing, although less readily acknowledged, central theme. When asked about whether she uses alcohol to enhance her mood or as a coping strategy to deal with conflict, anxiety, or depression, however, Mary stated:

No, no, I don't have a problem coping with things in my life. I actually am stronger when I'm coping with things in my life and other people's problems. I don't think to any extent no [re: using alcohol to cope]. But like I say, I use any excuse. I can say I drank because I was depressed. I drank because I was anxious. I drank for many reasons. I'm an alcoholic. I can't say that I drink for any one particular reason.

It was pointed out to Mary that she referred to needing to shut down several times during her interview and reported using alcohol to do so. She subsequently identified that she is usually focused on taking care of others' needs, rather than her own, and that when she drinks she wants to be alone; she doesn't want to have to be nice or take care of anyone else. Unlike her claim that she will drink for any reason or excuse, because she is an alcoholic, and further, that she doesn't drink for emotional coping reasons, she did articulate some reasons for her unmet needs which appear to resonate with her use of alcohol.

... And I think that in my everyday life, I need to back off . . . Being the way that I am with helping other people. And doing things for other people. And putting my own needs and my own wants aside to do for other people. So that I don't get to that point.

Despite her addiction story, competing stories emerged through exploring questions about Mary's needs. These included taking care of others at her own expense. The way that she deals with her needs is to shut down and isolate herself. Both Shelley's and Mary's stories reveal themes about unmet needs and feeling illequipped to meet them. For both women, alcohol appears to provide one means to do so. Yet, their dominant stories of being "addicts" have rendered competing stories of unmet needs.

Shelley and Mary moved in and out of conflicting discourses in their attempts to find explanations that fit. However, one explanation for this slipperiness is that it allows them to avoid holding onto a position for which they are accountable or have to address head on. This may be a known, or practised, way of being and thus comfortable. An advantage of not staying with a position, not holding still, is that it offers the capacity to escape or sidestep emotions posing emotional threat, danger, or difficulty. Further, their belief (like other women's in this study) that they have no choice over drinking is in many respects also about not claiming responsibility or accountability for their actions. They do not acknowledge their own agency.

When asked about what she might like about drinking, Mary responded, "But now I don't want to like any part of drinking," having difficulty seeing the difference between what she would like to be the case and what she actually feels. She imposes on herself what she wants to like, rather than acknowledge what she actually does like. Without recognition and awareness of what she likes about drinking, it will be difficult to find alternative, less harmful, behaviours that meet the same needs. These shifting discourses-gaps, uncertainties, and contradictions-should not go unexplored in harm-reduction treatment strategies, otherwise nothing much will change or be resolved. 
Although on the surface, many of the women seemed to emphasize a disease model, the presence of contradictions in their stories suggests it is possible that some women are trying to acknowledge the complexity of their experiences. They may actually be trying to transcend the either-or position that alcohol-related problems are either shaped by one's body (i.e., disease) or one's life (i.e., social-emotional context). Thus while they may be influenced by the dominant-culture stories of drinking problems as disease-based addictions, they may also know that their life experiences have played a significant role in their use of alcohol. It may be that the contradictions evident in their stories reveal an unresolved effort at holding onto the idea that their alcohol problems are related to women's bodies and women's lives (see Stoppard, 1997, 2000; Stoppard \& Gammell, 2003; Stoppard \& McMullen, 2003; Wiens, 2003). While at first glance these accounts appear contradictory, they may offer the possibility of greater complexity. However, by themselves, such contradictory stories do not appear to make much sense, and are suggestive of confusion, ambivalence, and uncertainty not atypical of the change process.

\section{Alternative Self-Definitions and Choices}

In contrast to most women in this study, some felt that controlled drinking was possible, and the harm-reduction strategy was their preference. Iris revealed that, “. . . to me that model sounds ideal, and it fits, most of how I see myself. . . . It is hard to say no forever. . . . I d don't think it would be hard to moderate. . . . I harm-reduced myself basically." Molly said about harm-reduction strategies: "I think it's grand. I really hate AA because of the attitude-I'm an alcoholic . . . It's kind of a defeatist attitude to me. I'm more than that . . . they put you in a box.” Morag was very articulate about the importance of harm reduction, particularly about what she described as dealing with the issues that may be causing the drinking, rather than simply abstaining. She said:

And so by addressing the whys, by empowering the person with skills, lending the thought that you won't need to drink next time ... I see that they do harm reduction that way. By dealing with the actual issues that may be causing the drinking rather than-okay drinking is bad ... That's useless. And I think they've realized that it is useless. It's about addressing and identifying your own issues prior to picking up that glass ...

These women valued and appreciated the opportunity to engage in the ongoing process of self-awareness necessary for small-step changes and increased control over one's alcohol-use choices. However, aside from this important dimension of harm reduction, they did not report receiving any formal training in controlleddrinking strategies. While programs for understanding change processes and strategies for gradual change are implemented, an organized or formal opportunity for training in controlled drinking does not exist in these programs.

\section{DISCUSSION}

These findings have implications for the continued development of harmreduction treatment strategies. Consistent with the philosophy of harm reduction, the emphasis in the program of the study is on individual choice between goals of abstinence or controlled use. Clients received an initial orientation to the programming which provided some description of the harm-reduction philosophy. While offered treatment choice, most women defined themselves as addicts, adopted a disease metaphor of addiction, and continued to choose abstinence. These findings 
raise questions about whether clients make adequately informed choices, or receive sufficient education about harm reduction and controlled drinking.

Given the desire of some women to gain greater control over their alcohol use, and the fear many others hold that it isn't possible, it seems even more compelling that organized efforts at controlled-use training be made widely available. Women afraid of the idea of controlled use may especially benefit from skills provided in such training, skills that are necessary for managed use. The provision of these skills may aid in making an informed choice, prompting more women to try controlled use.

Because the approach within harm-reduction programs focuses on individual choice, there appears to be minimal direct challenge to the disease model, and to the underlying conceptual assumptions of addiction, relapse, detox, and abstinence, most women have clearly internalized from the dominant culture even prior to treatment. To some extent, however, offering controlled-drinking goals as an alternative to abstinence is an inherent challenge to the belief that alcoholism is a primary disease. Drawing on Stoppard and Gammell's (2003) research conclusions on women and depression, we concur that medicalized approaches can result in women's disempowerment, by shifting the focus away from social contexts which produce distress in women's lives. In addition, women in this study also reported that even though they are participating in harm reduction based programming, both the legal system and child welfare typically demand abstinence. Wild (1999) reports that the attitudes which condone compulsory treatment and attitudes which condone harm reduction are incompatible. While compulsory treatment may have the effect of reducing individual or social harm it does not offer individuals the right to choose treatment, or the form of treatment. Moreover, its punitive approach is not consistent with the philosophy of harm reduction.

Influenced by ideas generated within contemporary feminist and narrative theory, we argue that dominant disease-based addiction discourse is at odds with a harm-reduction philosophy (Bordo, 1993; Brown, 1994, 2003a; Butler \& Scott, 1992; Foucault, 1980a, 1980b; Gormond, 1993; Haraway, 1988, 1990; Nicholson, 1990; Madigan, \& Law, 1998; Sands \& Nuccio, 1992; Scott, 1988; 1992; White \& Epston, 1990). For example, Alexander and Van de Vijngaart (1997) describe the intensity of moralistic and judgmental attitudes which often correspond with an absolutist belief in abstinence as a "temperance mentality." In their research, they found that when people were educated about harm reduction these kinds of attitudes were minimized and that they were subsequently more open to harm-reduction approaches.

Narrative theory influenced by postmodernism recognizes that while women often internalize dominant social stories about addiction and its treatment, many of these stories do not work well for them (Adams-Westcot, Dafforn, \& Sterne, 1993; Hare-Mustin 1994; Sanders, 1998; White 1991, 1994, 2001; Winslade \& Smith, 1997). A blended feminist narrative approach provides a framework to explore the ways that dominant stories of addiction help or hinder women in harm-reductionbased treatment. This critical lens of inquiry enables an analysis of the context of this discourse and its potential impact on women seeking treatment. It draws our attention to how dominant addiction discourse can become taken for granted and unquestioned within everyday life, obscuring potentially beneficial interpretations and possibilities for women. While the emphasis on individual women's choices within harm-reduction programming appears to be neutral, it doesn't take into account the social discourse which often predetermines or shapes choosing abstinence. 
In their review of the effectiveness of treatment programming for substance abuse in women, Ashley, Marsden, and Brady (2003) report that women experience gender-specific barriers to treatment including health risks, biology, social contexts in which addictions occur, and the social consequences of having a drinking problem (i.e., having one's children placed in care). Subsequently, their treatment needs are markedly different than men's. In addition to developing drinking problems with lower alcohol intake than men and experiencing greater health risks, overlapping issues of eating disorders, depression, sexual trauma or abuse, and domestic violence suggest the need for comprehensive and overlapping treatment for women (Brady \& Randall, 1999; Brady et al., 1993; Greenfield, 2002; Herman, 1992; Kaplan 1991; Najavits, 2002; Pirisi, 2000; Plant 1997; Stewart \& Israeli, 2003). Dominant addiction discourses ignore these contexts, situating alcohol use as the only problem that needs to be addressed. It is these gender-specific differences which have lead to women-centered and women's-only programming. Since little is known to date on the effectiveness of harm reduction based programs for women, this study contributes to knowledge in this area.

Abstinence-based approaches (cold turkey) often focus on absolute behavioural change with less attention to why one is drinking. The assumption is that one drinks because one is an alcoholic. This paradigm inherently restricts a whole range of questions about drinking behaviour, and its meaning and purpose which are critical to finding less harmful alternatives. Of significance is the degree of contradiction about these concepts within women's stories themselves. For instance, a woman may be opposed to harm reduction because she believes she is an addict who has no control over drinking alcohol and, as such, she must abstain from it. She may simultaneously provide psycho-social explanations of her drinking behaviour by connecting binge drinking to a history of trauma or abuse. She may additionally describe a history of depression, and a desire to numb or remove herself from difficult feelings through drinking. Stories like this provide competing and complex accounts of drinking behaviour.

This is fertile ground for further development in harm-reduction programming and from a therapeutic perspective the results are suggestive of an entry point for potentially valuable clinical exploration and discovery. While ambivalence and uncertainty are common aspects of the change process, they need to be acknowledged and explored if treatment is to be effective. Harm-reduction programming may then need to deliberately attend to contradiction, ambivalence, and uncertainty, rather than move people too quickly into the either-or position of abstinence or controlled use. This also suggests that psycho-education and awareness training may need to be further emphasized during the initial treatment choices clients make, reflecting the assumption that they may be more uncertain than definite about what will work for them. It is helpful that harm-reduction services in this study encourage service users to move between these two positions.

This research suggests that without providing education and training in controlled drinking, the focus on individual choice is limited and fails to adequately educate women on the ideological assumptions and practices of medically-based abstinence models. Perhaps further investigation will determine whether these practices occur across Canada, and provide exploration of the role of the therapist/ program in the process of clients' treatment choices. Thus, while programs offer alternatives to the disease metaphor such as the possibility of controlled use, abstinence-based women's treatment within harm-reduction programming doesn't actually dispute the disease metaphor. The significance of continuing to reinforce the 
disease model with harm-reduction programming is an issue that may also require further investigation. We need to ask what the implications are of theoretically offering alternatives to the disease metaphor while most women do not choose these alternatives.

Admittedly, while there is a desire not to overly influence the choices individuals make, findings here suggest that the choices currently made are overly influenced by pre-existing dominant social discourse about addiction. To balance the effects of this dominant ideology, more sustained effort at educating women about the full range of possibilities and formal training in controlled drinking are needed. Only by systematically providing this balance can it be said that women have made an adequately informed choice. Further, if more education and skills in controlled drinking need to be provided in order to offer women an informed choice, the role of therapists and programming itself need to be examined (Hore, 1995). These findings reveal potential tensions and ambivalence centered around the choice of controlled use or abstinence which are likely to effect the implementation of harm reduction.

\section{CONCLUSION}

Research findings discussed in this paper suggest that psycho-education on harm reduction may need to address internalized dominant discourse such as the medicalization of addiction. Also, training in controlled drinking may advance the delivery of harm-reduction services for women. Findings suggest a more proactive approach to harm reduction by including education on harm reduction and more purposeful integration of these principles into treatment practices, specifically, skills training for controlled use. These findings lend support to the argument that feminist approaches to working with women's use of alcohol and other substances need to challenge discourses which may be harmful to women. Women's dominant addiction stories need to be unpacked to discover competing stories about their lives which may be valuable in making well thought-out treatment choices. Stories which contextualize women's pain, suffering, and trauma, for instance, may be discounted under the weight of the powerful story of addiction as disease. Future research in this area needs to explore, in further depth, the sources of exposure to dominant addiction discourse including previous medical treatment, Alcoholics Anonymous, history of alcohol treatment, media and the culture at large, and should aim to determine the impact of this exposure on women's treatment choices and outcomes. Findings in this study suggest that for harm reduction to work most effectively there needs to be greater emphasis on ensuring that clients' choices are well-informed. This will involve balancing the dominance of disease-based abstinence approaches with both the psycho-education and skills training needed to allow for the full range of choices that harm-reduction services are well positioned to offer.

\section{NOTES}

1. The larger study explored the relationship between binge eating and binge drinking among women in treatment for alcohol use problems. Thus all of the women participating in the interviews had a co-existing problem of binge eating and binge drinking. Participants were recruited through Addiction Prevention and Treatment Services and provided well-informed consent at each stage of the research.

2. Ethical approval was attained through the Capital District Health Authority Research Ethics Board. Written informed consent was obtained from the research participants prior to data collection. 


\section{HARM REDUCTION AND WOMEN}

3. Focus groups generate additional information beyond the individual interviews. The group interview structure of focus groups provides an interactive approach, likely to yield rich data, and deeper discussion may be stimulated by varying positions and opinions (Kitzinger, 1994; Morgan, 1998). The focus group revisited the themes of the individual interviews. While this allowed for the possibility of new themes emerging we did not find that to be the case in this study. The focus group conversation between women also highlight similarities and differences in women's perspectives.

4. Names associated with quotes from participants are not real. All participants' names have been changed to pseudonyms that they chose for themselves.

\section{RÉSUMÉ}

Cet article traite des objectifs choisis par des femmes participant aux programmes de réduction des méfaits reliés à l'usage d'alcool, en termes de consommation contrôlée et d'abstinence. Les auteurs situent leurs recherches dans le contexte des débats entourant les objectifs de contrôle ou d'abstinence et abordent principalement les besoins des femmes en matière de traitement. Des résultats révèlent que les femmes en traitement pour des problèmes de consommation d'alcool sont souvent caractérisées par une profonde intériorisation d'idéologies sociales dominantes concernant la toxicomanie. Les résultats tendent à démontrer que dans le cas où elles ont le choix entre des objectifs d'abstinence et de consommation contrôlée, la plupart des femmes se définissent comme «toxicomanes », adoptent une métaphore reliée à la maladie pour définir " la toxicomanie » et choisissent l'abstinence. Ces constatations soulèvent des interrogations sur la qualité des informations que reçoit la clientèle à propos de la réduction des méfaits et de la consommation contrôlée, ainsi que sur sa capacité d'effectuer des choix éclairés.

\section{REFERENCES}

Adams-Westcot, J., Dafforn, T., \& Sterne, P. (1993). Escaping victim life stories and coconstructing personal agency. In S. Gilligan \& R. Price (Eds.), Therapeutic conversations (pp. 258-276). New York: W.W. Norton.

Alexander, B., \& Van de Vijngaart, G. (1997). Readiness for harm reduction: Coming to grips with the 'temperance mentality.' In P. Erickson, D. Riley, Y. Cheung, \& P., O'Hare (Eds.), Harm reduction: A new direction for drugs, policies, and programs (pp. 80-98). Toronto: University of Toronto Press.

Anderson, P. (1995). Controlled drinking and a public health approach to alcohol. Addiction, 90(9), 1162-1164.

Armor, D., Polich, J., \& Stambul, H. (Eds.). (1978). Alcoholism and treatment. New York: Wiley.

Ashley, O., Marsden, M., \& Brady, K.T. (2003). Effectiveness of substance abuse treatment programming for women: A review. The American Journal of Drug and Alcohol Use, 29, 19-53.

Bepko, C. (Ed.). (1991). Feminism and addiction. New York: Haworth Press.

Blume, A., Anderson, B., Fader, J., \& Marlatt, G.A. (2001). Harm reduction programs: Progress rather than perfection. In R.H. Coombs (Ed.), Addiction recovery tools: A practical handbook (pp. 367-382). Thousand Oaks, CA: Sage.

Booth, P. (1984). Problem drinkers' goal choice and treatment outcomes: A preliminary study. Addictive Behaviors, 9, 357-364.

Bordo, S. (1993). Feminism, postmodernism, and gender-skepticism. In S. Bordo, Unbearable weight: Feminism, western culture, and the body (pp. 215-243). Berkeley, CA: University of California Press.

Brady, K., \& Randall, C. (1999). Gender differences in substance use disorders. The Psychiatric Clinics of North America, 22, 241-252.

Brady, K., Grice, D., Dustan, L., \& Randall, C. (1993). Gender differences in substance use dis- 


\section{CANADIAN JOURNAL OF COMMUNITY MENTAL HEALTH}

orders. American Journal of Psychiatry, 150, 1707-1711.

Brown, C. (1994). Feminist postmodernism and the challenge of diversity. In A. Chambone \& A. Irving (Eds.), Essays on postmodernism and social work (pp. 35-48). Toronto: Canadian Scholars' Press.

Brown, C. (2003a). Narrative therapy: Reifying or challenging dominant discourse. In W. Shera (Ed.), Emerging perspectives on anti-oppressive practice (pp. 223-246). Toronto: Canadian Scholars Press.

Brown, C. (2003b). Deconstructing women's narratives in feminist research: Women's stories about co-existing problem eating and drinking. Paper presented at the Congress of the Humanities and Social Sciences, Canadian Association of Social Work, Halifax, Canada, June.

Butler, J., \& Scott, J. (1992). Feminists theorize the political. New York: Routledge.

Connors, N., \& Franklin, K. (2000). Using focus groups to evaluate client satisfaction in an alcohol and drug treatment program. Journal of Substance Abuse Treatment, 18, 313-320.

Connors, G., \& Walitzer, K. (1997). Harm reduction interventions with women who are heavy drinkers. In P. Erickson, D. Riley, Y. Cheung, \& P. O’Hare. (Eds.). Harm reduction: A new direction for drug policies and programs (pp. 290-302). Toronto: University of Toronto Press.

Davies, D. (1962). Normal drinking in recovered alcohol addicts. Quarterly Journal of Studies on Alcohol, 23, 93-104.

Denning, P. (2000). Practicing harm reduction psychotherapy. New York: Guilford Press.

Dorn, N. (1995). Sideshow: An appreciation and critique of Dutch drug policies. British Journal of Addiction, 84, 995-997.

Engelsman, E. (1989). Dutch policy on the management of drug-related problems. British Journal of Addictions, 84, 211-218.

Erickson, P., Riley, D., Cheung, Y., \& O’Hare, P. (Eds.). (1997). Harm reduction: A new direction for drug policies and programs. Toronto: University of Toronto Press.

Finch, J. (1984). It's great to have someone to talk to: The ethics and politics of interviewing women. In C. Bell \& H. Roberts (Eds.), Social researching: Politics, problems, practice (pp. 70-87). London: Routledge and Kegan Paul.

Fingarette, H. (1988). Heavy drinking: The myth of alcoholism as disease. Berkeley, CA: University of California Press.

Finney, J., \& Moos, R. (1981). Characteristics and prognoses of alcoholics who become moderate drinkers and abstainers after treatment. Journal of Studies on Alcohol, 42, 94-105.

Fischer, B. (1997). The battle for new Canadian drug law: A legal basis for harm reduction or a new rhetoric for prohibition? A chronology. In P. Erickson, D. Riley, Y. Cheung, \& P. O'Hare (Eds.), Harm reduction: A new direction for drug policies and programs (pp. 4768). Toronto: University of Toronto Press.

Foucault, M. (1980a). The history of sexuality (Vol. 1): An introduction. New York: Vintage.

Foucault, M. (1980b). Power/knowledge: Selected interviews and other writings 1972-1977. New York: Pantheon.

Glaser, B., \& Strauss, A. (1967). The discovery of grounded theory: Strategies for qualitative research. Chicago, IL: Aldine.

Gormond, J. (1993). Postmodernism and the conduct of inquiry in social work. Affilia, 8, 247-264.

Greenfield, S. (2002). Women and alcohol use disorders. Harvard Review of Psychiatry, 10, 7685.

Haraway, D. (1988). Situated knowledges: The science question in feminism and the privilege of partial perspective. Feminist Studies, 14, 575-599.

Haraway, D. (1990). A manifesto for cyborgs: Science, technology, and socialist feminism in the 1980s. In L. Nicholson (Ed.), Feminism/Postmodernism (pp. 190-233). New York: Routledge.

Hare-Mustin, R. (1994). Discourses in the mirrored room: A postmodern analysis of therapy. Family Processes, 33, 19-35.

Heather, N. (1993). Application of harm-reduction principles to the treatment of alcohol problems. In N. Heather, A. Wodak, E. A. Nadelmann, \& P. O’Hare (Eds.), Psychoactive drugs and harm reduction: From faith to science (pp. 168-183). London, UK: Whurr. 


\section{HARM REDUCTION AND WOMEN}

Heather, N. (1995). The great controlled drinking consensus: Is it premature? Addiction, 90, 1160-1162.

Heather, N., \& Roberson, I . (1981). Controlled drinking. New York: Methuen.

Herman, J. (1992). Trauma and recovery: The aftermath of violence-from domestic abuse to political terror. New York: Basic Books.

Hore, B. (1995). You can't just leave the goal choice to the patient. Addiction, 90, 1172-1173.

Hurst, S.A. (1999). Legacy of betrayal: A grounded theory of becoming demoralized from the perspective of women who have been depressed. Canadian Psychology, 40, 179-191.

Inciardi, J., \& Harrison, L. (Eds.) (2000). Harm reduction: National and international perspectives. Thousand Oaks, CA: Sage.

Jacobs, M., Fox Keller, S., \& Shuttleworth, S. (1990). Body/politics: Women and the discourse of science. New York: Routledge.

Kaplan, S. (1991). Child abuse and alcoholism in women: A feminist approach to treatment. Canadian Women's Studies, 12, 67-70.

Kitzinger, J. (1994). The methodology of focus groups: The importance of interaction between research participants. Sociology of Health and Illness, 16, 103-121.

Madigan, S., \& Law, I. (1998). Praxis: Situating discourse, feminism, and politics in narrative therapies. Vancouver: Cardigan Press.

Marlatt, G.A. (1998). Basic principles and strategies of harm reduction. In G.A. Marlatt (Ed.), Harm reduction: Pragmatic strategies for managing high risk behaviours (pp. 49-66). New York: Guilford Press.

Marlatt, G.A. (1983). The controlled drinking controversy: A commentary. American Psychologist, 38(10), 1097-1110.

Marlatt, G.A., Larimer, M., Baer, J., \& Quigley, L. (1993). Harm reduction for alcohol problems: Moving beyond the controlled drinking controversy. Behavior Therapy, 24, 461-504.

Mies, M. (1983). Toward a methodology for feminist research. In G. Bowles \& R. Klein (Eds.), Theories of women's studies (pp. 117-139). Boston: Routledge \& Kegan Paul.

Mies, M. (1991). Women's research or feminist research? The debate surrounding feminist science and methodology. In M. Fonow, \& J. Cook (Eds.). Beyond methodology: Feminist scholarship as lived research (pp. 60-84). Indianapolis, IN: Indiana University Press.

Miller, W. (1983). Controlled drinking: A history and a critical review. Journal of Studies on Alcohol, 44, 68-83.

Miller, W., \& Joyce, M. (1979). Prediction of abstinence, controlled drinking, and heavy drinking outcomes following behavioural self-control training. Journal of Consulting and Clinical Psychology, 47, 773-775.

Morgan, D. (1998). The focus group guidebook: Focus group kit 1. Thousand Oaks, CA: Sage.

Morgan, P., \& Cohen, L. (1993). Controlled drinking advocates challenge use of abstinence model in treatment of addictions. Canadian Medical Association Journal, 149, 706-713.

Morse, J., \& Field, P. (1995). Qualitative research methods for health professionals. Thousand Oaks, CA: Sage.

Najavits, L. (2002). A woman's addiction workbook: Your guide to in-depth healing. Oakland, CA: New Harbinger.

Nicholson, L. (Ed.). (1990). Feminism/postmodernism. New York: Routledge.

Oakley, A. (1981). Interviewing women: A contradiction in terms. In H. Roberts (Ed.), Doing feminist research (pp. 30-61). London: Routledge and Kegan Paul.

Ogborne, A. (1987). A note on the characteristics of alcohol abusers with controlled drinking aspirations. Drug and Alcohol Dependence, 19, 159-164.

Orford, J., \& Keddie, A. (1986). Abstinence or controlled drinking in clinical practice: A test of the dependence and persuasion hypothesis. British Journal of Addiction, 81, 495-504.

Pasick, P., \& White, C. (1991). Challenging General Patton: A feminist stance in substance abuse treatment and training. In C. Bepko (Ed.), Feminism and addiction (pp. 87-102). New York: Haworth Press.

Peele, S. (1985a). The meaning of addiction: Compulsive experience and its interpretation. Toronto: Lexington Books.

Peele, S. (1985b). The meaning of addiction: An unconventional view. San Francisco, CA: Jossey-Bass.

Pirisi, A. (2000). Alcohol's siege on women's health. Journal of Addictions and Mental Health, 


\section{CANADIAN JOURNAL OF COMMUNITY MENTAL HEALTH}

$3,13$.

Plant, M. (1997). Women and alcohol: Contemporary and historical perspectives. New York: Free Association Books.

Pokorny, A.D., Miller, B.A., \& Kaplan, H.B. (1972). The brief MAST: A shortened version of the Michigan Alcoholism Screening Test. American Journal of Psychiatry, 129, 342-345.

Rabinow, P. (Ed.). (1984). The Foucault reader. New York: Pantheon Books.

Reinharz, S. (1992). Feminist methods in social research. New York: Oxford University Press.

Riley, D., \& O’Hare, P. (2000). History, definition, and practice. In J. Inciardi \& L. Harrison (Eds), Harm reduction: National and international perspectives (pp. 1-26). Thousand Oaks, CA: Sage.

Room, R. (1997). Harm reduction, human rights, and the WHO expert committee on drug dependence. In P. Erickson, D. Riley, Y. Cheung, \& P. O'Hare (Eds.), Harm reduction: A new direction for drug policies and programs (pp. 119-130). Toronto: University of Toronto Press.

Rosenberg, H. (1993). Prediction of controlled drinking by alcoholics and problem drinkers. Psychological Bulletin, 113, 129-139.

Sanchez-Craig, M., Davila, R., \& Cooper, G. (1996). Self-help approach for high-risk drinking: Effects of an initial assessment. Journal of Consulting and Clinical Psychology, 64, 694700 .

Sanchez-Craig, M., Leigh, G., Spivak, K., \& Lei, H. (1989). Superior outcome of females over males after brief treatment for the reduction of heavy drinking. British Journal of Addiction, 84, 395-404.

Sanders, C. (1998). Substance misuse dilemmas: A postmodern inquiry. In S. Madigan \& I. Law (Eds.), Praxis: Situating discourse, feminism and politics in narrative therapies (pp. 141162). Vancouver: Cardigan Press.

Sands, R., \& Nuccio, R. (1992). Postmodern feminist theory and social work. Social Work, 37, 489-494.

Scott, J. (1988). Deconstructing equality-versus-difference: Or the uses of poststructuralist theory for feminism. Feminist Studies, 14, 33-50.

Scott, J. (1992). Experience. In J. Butler \& J. Scott (Eds.), Feminists theorize the political (pp. 22-40). New York: Routledge.

Sobell, M., \& Sobell, L. (1973). Alcoholics treated by individualized behaviour therapy: One year treatment outcomes. Behaviour Research and Therapy, 11, 599-618.

Sobell, M., \& Sobell, L. (1976). Second year treatment outcome of alcoholics treated by individualized behaviour therapy: Results. Behaviour Research and Therapy, 14, 195-215.

Sobell, M., \& Sobell, L. (1995). Controlled drinking after 25 years [Editorial]. Addiction, 90, 1149-1153.

Stanley, L., \& Wise, S. (1990). Method, methodology and epistemology in feminist research processes. In L. Stanley (Ed.), Feminist praxis (pp. 20-60). New York: Routledge.

Stern, P.N., \& Pyles, S.H. (1985). Using grounded theory methodology to study women's culturally based decisions about health. In P.N. Stern (Ed.), Women, health, and culture (pp. 1-24). Washington, DC: Hemisphere.

Stewart, S.H., Brown, C., Theakston, J., Devoulyte, K., \& Larsen, S. (In press). Why do women with alcohol problems binge eat? Exploring connections between binge eating and heavy drinking in women receiving treatment for alcohol problems. Journal of Health Psychology.

Stewart, S.H., \& Isreali, A. (2003). Substance abuse and co-occurring psychiatric disorders in victims of violence. In C. Wekerle \& A.M. Wall (Eds.), The violence and addiction equation: Theoretical and clinical issues in substance abuse and relationship violence (pp. 98122). New York: Brunner-Mazel.

Stoppard, J. (1997). Women’s bodies, women's lives and depression. Towards a reconciliation of material and discursive accounts. In J. Ussher (Ed.), Body talk: The material and discursive regulation of sexuality, madness, and reproduction (pp. 10-29). New York: Routledge.

Stoppard, J. (2000). Understanding depression: Feminist social constructionist approaches. New York: Routledge.

Stoppard, J., \& Gammell, D. (2003). Depressed women's treatment experiences: Exploring themes of medicalization and empowerment. In J. Stoppard \& L. McMullen (Eds.), Situating sadness: Women and depression in social context (pp. 39-61). New York: New 


\section{HARM REDUCTION AND WOMEN}

York University Press.

Stoppard, J., \& McMullen, L. (Eds.) (2003). Situating sadness: Women and depression in social context. New York: New York University Press.

Strauss, A., \& Corbin, J. (1990). Basics of qualitative research: Grounded theory procedures and techniques. Newbury Park, CA: Sage.

Tatarsky, A. (1998). An integrative approach to harm reduction psychotherapy: A case of problem drinking secondary to depression. In session. Psychotherapy in Practice, 4, 9-24.

Tatarsky, A. (2002). Harm reduction psychotherapy: A new treatment. Northvale, NJ: Larson Aronson.

Weisner, C. (1995). Controlled drinking issues in the 1990s: The public health model and speciality treatment. Addiction, 90, 1164-1166.

White, M. (1991). Deconstruction and therapy. Dulwich Centre Newsletter, 3, 21- 40.

White, M. (2001). Narrative practice and the unpacking of identity conclusions. Gecko: A Journal of Deconstruction and Narrative Ideas in Therapeutic Practice, 1, 28-55.

White, M. (1994). The politics of therapy: Putting to rest the illusion of neutrality. Adelaide, South Australia: Dulwich Centre Publications.

White, M. (2001). Narrative practice and the unpacking of identity conclusions. Gecko: A Journal of Deconstruction and Narrative Ideas in Therapeutic Practice, 1, 28-55.

White, M., \& Epston, D. (1990). Narrative means to therapeutic ends. New York: W.W. Norton.

World Health Organization. (1996). A cross-national trial of brief interventions with heavy drinkers. American Journal of Public Health, 86(7), 948-955.

Wiens, J. (2003). Depression and decision-making: A material-discursive analysis of antidepressant use in women. Unpublished Master's thesis, Dalhousie University, Halifax, Canada.

Wild, T.C. (1999). Compulsory substance-user treatment and harm reduction: A critical analysis. Substance Use and Misuse, 34, 83-102.

Winslade, J., \& Smith, L. (1997). Countering alcoholic narratives. In G. Monk, J. Winslade, K. Crocket, \& D. Epston (Eds.), Narrative therapy in practice: The archaeology of hope (pp. 158-192). San Francisco, CA: Jossey Bass. 